\title{
Synthesis and Properties of Polyimides Derived from 1,4-Bis(4-aminophenoxy)-2-tert-butylbenzene
}

\author{
Der-Jang LIAW ${ }^{\dagger}$ and Been-Yang LiAW \\ Department of Chemical Engineering, National Taiwan Institute of Technology, \\ Taipei, Taiwan 106, Republic of China
}

(Received April 30, 1996)

\begin{abstract}
The novel diamine containing bulky tert-butyl substituent, 1,4-bis(4-aminophenoxy)-2-tert-butylbenzene (BATB) was used as monomer with various aromatic tetracarboxylic dianhydrides to synthesize polyimides via a conventional two-stage procedure that included ring-opening polyaddition in a polar solvent such as $N, N$-dimethylacetamide (DMAc) to give poly(amic acid)s, followed by cyclodehydration to polyimides. BATB(II) was prepared through the nucleophilic displacement of tert-butylhydroquinone with $p$-chloronitrobenzene in the presence of $\mathrm{K}_{2} \mathrm{CO}_{3}$, followed by catalytic reduction. Depending on the dianhydride used, the poly(amic acid)s obtained had inherent viscosities of $0.76-1.79 \mathrm{dL} \mathrm{g}^{-1}$. All poly(amic acid)s could be cast from the DMAc solutions and thermally converted to transparent, flexible, and tough polyimide films. The polyimide films had high tensile strength of $122-208 \mathrm{MPa}$, an elongation at breaks of $3-9 \%$, and a tensile modulus of $1.92-2.68 \mathrm{GPa}$. Polyimides from 4,4'-sulfonyldiphthalic anhydride and 4,4'-hexafluoro-isopropylidenediphathalic anhydride had better solubility than the other polyimides. These polyimides had glass transition temperatures between $240-268^{\circ} \mathrm{C}$ and $10 \%$ mass loss temperatures were recorded at $479-522^{\circ} \mathrm{C}$ in nitrogen.

KEY WORDS 1,4-Bis(4-aminophenoxy)-2-tert-butylbenzene / Poly(amic acid) / Polyimides /
\end{abstract}

Polyimides have been investigated extensively and used widely over the past three decades because of high performance properties such as good thermal, mechanical, and electrical properties. ${ }^{1-3}$ Unless carefully designed, however, polyimides are often insoluble and have high softening temperature, presenting serious processing difficulties. Therefore, the preparation of soluble or thermoplastic polyimides has been a major research interest.

Several approaches such as the incorporation of flexible bridging linkages ${ }^{4-8}$ or meta-oriented or orthooriented phenylene rings ${ }^{9,10}$ into polymer backbone, and introduction of bulky substituents ${ }^{11-15}$ along polymer backbone has led to considerable success.

Aromatic ether linkages inserted in aromatic main chains provide them with significantly lower energy of internal rotation. In general, such a structural modification leads to lower glass transition temperature and crystalline melting temperature as well as significant improvement in solubility and other process characteristics of the polymers without greatly sacrificing thermal stability.

The introduction of a monosubstituted monomer into the polymer chain is expected to decrease of order along the chain, enhanced solubility, and reduced crystallinity due to a random arrangement of substituents. ${ }^{16-22}$ Some previous articles ${ }^{17-21}$ that introducing a tert-butyl substituent monomer into polyester and poly(ether ether ketone) backbone lowers transition temperatures and improves solubility properties. However, there is little literature ${ }^{23}$ on the characteristic of introducing tert-butyl group into polyimides.

The present article describes the successful synthesis of a new diamine containing aryl ether and tert-butyl aromatic ring, 1,4-bis(4-aminophenoxy)-2-tert-butylbenzene, and use for the preparation of polyimides by the polymerization of the diamine with various aromatic tetracarboxylic dianhydrides. Chemical and thermal cy-

\footnotetext{
† To whom correspondence should be addressed.
}

clodehydration were performed in this study. Percent imidization, solubility, thermal and mechanical properties, and X-ray diffraction patterns were investigated and are discussed.

\section{EXPERIMENTAL}

\section{Materials}

Materials, tert-butylhydroquinone (from Janssen), $p$ chloronitrobenzene (from Merck), anhydrous potossium carbonate (from Janssen), hydrazine monohydrate (from Janssen), and $10 \%$ palladium on activated carbon (from Merck) were used as received. Reagent grade aromatic tetracarboxylic dianhydrides such as pyromellitic dianhydride (PMDA, III ; from CHRISKEV), 3,3'4,4'-biphenyltetracarboxylic dianhydride (BPDA, $\mathrm{III}_{\mathrm{b}}$; from CHRISKEV), 4,4'-oxydiphthalic anhydride (ODPA, III from TCI), 3,3',4,4'-benzophenonetetracarboxylic dianhydride (BTDA, III $_{\mathrm{d}}$; from CHRISKEV), 4,4'-sulfonyldiphthalic anhydride (SDPA, III $_{e}$; from New Japan Chemical Co.), and 4,4'-hexafluoro-isopropylidenediphathalic anhydride $\left(6 \mathrm{FDA}, \mathrm{III}_{\mathrm{f}}\right.$; from CHRISKEV) were recrystallized from acetic anhydride before use. $N, N$-Dimethylacetamide (DMAc) and pyridine were purified by distillation under reduced pressure over calcium hydride and stored over $4 \AA$ molecular sieves. Acetic anhydride was purified by vacuum distillation.

\section{Monomer Synthesis}

1,4-Bis(4-nitrophenoxy)-2-tert-butylbenzene (BNTB, I). This compound was synthesized by reaction of tertbutylhydroquinone $(41.5 \mathrm{~g}, 0.25 \mathrm{~mol})$ and $p$-chloronitrobenzene $(81.9 \mathrm{~g}, 0.52 \mathrm{~mol})$ in the presence of potassium carbonate $(79.4 \mathrm{~g}, 0.57 \mathrm{~mol})$ and $N, N$-dimethylformamide $(300 \mathrm{~mL})$ at $160^{\circ} \mathrm{C}$ for $8 \mathrm{~h}$. The mixture was cooled and poured into $600 \mathrm{~mL}$ of ethanol-water $(1: 1$ by volume). The crude product was recrystallized from glacial acetic acid to provide brown needle $\left(\mathrm{mp} 154^{\circ} \mathrm{C}\right)$ in $85 \%$ yield. The IR spectrum (KBr) exhibited absorptions at 1509 
and $1335 \mathrm{~cm}^{-1}\left(\mathrm{NO}_{2}\right)$, and $1233 \mathrm{~cm}^{-1}(\mathrm{C}-\mathrm{O}-\mathrm{C})$.

${ }^{1} \mathrm{H}$ NMR $\left(\mathrm{CDCl}_{3}\right): \delta(\mathrm{ppm})=1.33(\mathrm{~s}, 9 \mathrm{H}), 6.91(\mathrm{~s}$, 2H), 7.03 (dd, 4H), 7.19 (s, 1H), 8.19 (dd, 4H). ${ }^{13} \mathrm{C}$ NMR $\left(\mathrm{CDCl}_{3}\right): \delta(\mathrm{ppm})=29.91,34.91,116.86,117.21,119.08$, $120.13,123.06,125.87,125.95,142.59,144.49,150.58$, 151.26, 163.09, 163.15. Anal. Calcd for $\mathrm{C}_{22} \mathrm{H}_{20} \mathrm{O}_{6} \mathrm{~N}_{2}$ : C, $64.70 \%$; H, 4.90\%; N, 6.86\%. Found: C, 64.52\%; H, $4.79 \% ; \mathrm{N}, 6.42 \%$.

1,4-Bis(4-aminophenoxy)-2-tert-butylbenzene (BATB, II). The obtained dinitro compound $(57.1 \mathrm{~g}, 0.14 \mathrm{~mol})$, $0.3 \mathrm{~g}$ of $10 \% \mathrm{Pd}-\mathrm{C}$, and $400 \mathrm{~mL}$ ethanol were introduced into a three-necked flask to which $130 \mathrm{~mL}$ of hydrazine monohydrate was added dropwise over a period of $1 \mathrm{~h}$ at $85^{\circ} \mathrm{C}$. After the addition was complete, the reaction was continued at reflux temperature for an additional $24 \mathrm{~h}$. The mixture was then filtered to remove $\mathrm{Pd}-\mathrm{C}$. After cooling, the precipitated needle crystals were isolated by filtration and recrystallized from ethanol in $83 \%$ yield $\left(\mathrm{mp} 134^{\circ} \mathrm{C}\right)$. The IR spectrum $(\mathrm{KBr})$ exhibited absorptions at 3364 and $3440 \mathrm{~cm}^{-1}(\mathrm{~N}-\mathrm{H})$, and $1203 \mathrm{~cm}^{-1}$ (C-O-C).

${ }^{1} \mathrm{H}$ NMR $\left(\mathrm{CDCl}_{3}\right): \delta(\mathrm{ppm})=1.40(\mathrm{~s}, 9 \mathrm{H}), 3.55(\mathrm{~s}$, $4 \mathrm{H}), 6.61-6.67(\mathrm{~m}, 6 \mathrm{H}), 6.81(\mathrm{dd}, 4 \mathrm{H}), 7.05(\mathrm{~d}, 1 \mathrm{H})$. ${ }^{13} \mathrm{C}$ NMR $\left(\mathrm{CDCl}_{3}\right): \delta(\mathrm{ppm})=29.85,34.74,115.31$, $116.23,116.30,116.91,119.73,120.12,141.42,141.72$, 141.91, 149.50, 150.21, 151.85, 153.06. Anal. Calcd for $\mathrm{C}_{22} \mathrm{H}_{24} \mathrm{O}_{2} \mathrm{~N}_{2}$ : C, 75.86\%; H, 6.89\%; N, 8.04\%. Found: C, $75.44 \%$; H, 6.87\%; N, 7.70\%.

\section{Polymerization}

A typical example of polymerization is as follows. To a stirred solution of $0.87 \mathrm{~g}(2.5 \mathrm{mmol})$ of BATB in 13.5 $\mathrm{mL}$ of DMAc, was added gradually $0.545 \mathrm{~g}(2.5 \mathrm{mmol})$ of PMDA. The mixture was stirred at room temperature for $2 \mathrm{~h}$ under an argon atmosphere. The inherent viscosity of the poly(amic acid) in DMAc was $1.79 \mathrm{dL} \mathrm{g}^{-1}$, as measured at $0.5 \mathrm{~g} \mathrm{dL}^{-1}$ at $30^{\circ} \mathrm{C}$. The poly(amic acid) solution thus obtained was spread on a glass plate and the solvent was removed at $80^{\circ} \mathrm{C}$. Imidization was carried out by thermal cyclodehydration of the poly(amic acid) film by sequential heating at 110, 150, 180, 210, 250, and $300^{\circ} \mathrm{C}$ for $20 \mathrm{~min}$ each. The IR spectrum (KBr) exhibited absorptions at 1729 and $1771 \mathrm{~cm}^{-1}(\mathrm{C}=\mathrm{O})$, and 1366 $\mathrm{cm}^{-1}(\mathrm{C}-\mathrm{N})$.

Chemical cyclodehydration was also carried out by adding a mixture of acetic anhydride and pyridine (volume ratio $2: 1$ ) to the above mentioned poly(amic acid) solution. The mixture was stirred at room temperature for $1 \mathrm{~h}$, and then at $100^{\circ} \mathrm{C}$ for $3 \mathrm{~h}$. The polymer solution was poured into methanol. The yellow precipitate was collected by filtration, washed thoroughly with methanol and hot water, and dried at $100^{\circ} \mathrm{C}$ under vacuum. The IR spectrum $(\mathrm{KBr})$ exhibited absorptions at 1721 and $1770 \mathrm{~cm}^{-1}(\mathrm{C}=\mathrm{O})$, and $1369 \mathrm{~cm}^{-1}(\mathrm{C}-\mathrm{N})$.

\section{Measurements}

IR spectra were recorded in the range $4000-400 \mathrm{~cm}^{-1}$ for the synthesized monomers and polymers in $\mathrm{KBr}$ disks with a JASCO IR-700 spectrometer. The inherent viscosities of all polyimides were measured at $0.5 \mathrm{~g} \mathrm{dL}^{-1}$ in concentrated sulfuric acid using an Ubbelohde viscometer. Elemental analysis was made with a Perkin-
Elmer 2400. Wide-angle X-ray diffraction patterns were obtained at room temperature with film specimens on an X-ray diffractomer with a Philips model PW 1710 using $\mathrm{Ni}$-filtered $\mathrm{Cu}-K_{\alpha}$ radiation $(40 \mathrm{kV}, 30 \mathrm{~mA})$. The scanning rate was $3 \mathrm{deg} \min ^{-1}$. NMR spectra were recorded with a Bruker AM-300 WB FT-NMR spectrometer. Thermogravimetric data were obtained on a du Pont 2200 in flowing nitrogen $\left(60 \mathrm{~cm}^{3} \mathrm{~min}^{-1}\right)$ at a heating rate of $20^{\circ} \mathrm{C} \mathrm{min}^{-1}$. Differential scanning calorimetry (DSC) analysis was performed on a Perkin-Elmer DSC-7 in flowing nitrogen $\left(30 \mathrm{~cm}^{3} \mathrm{~min}^{-1}\right)$ at a heating rate of $20^{\circ} \mathrm{C} \mathrm{min}^{-1}$. A LLOYD instrument with a load cell of $500 \mathrm{~N}$ was used to study the stress-strain behavior of the samples. A gauge of $2 \mathrm{~cm}$ and strain rate of $5 \mathrm{~cm} \mathrm{~min}^{-1}$ were used in this study. All measurements were performed at room temperature with film specimens $(0.5 \mathrm{~cm}$ wide, $6 \mathrm{~cm}$ long, and $c a .1 \mathrm{~mm}$ thick); the average of at least four individual determinations was used.

\section{RESULTS AND DISCUSSION}

\section{Monomer Synthesis}

A new diamine, 1,4-bis(4-aminophenoxy)-2-tert-butylbenzene (II), was synthesized in two steps by the aromatic nucleophilic displacement reaction of tert-butylhydroquinone and $p$-chloronitrobenzene, giving the dinitro compound (I), followed by reduction with hydrazine monohydrate/Pd-C (eq 1). The structures of the

$$
\begin{aligned}
& \mathrm{HO}-\left\langle\mathrm{O}-\mathrm{OH}+2 \mathrm{O}_{2} \mathrm{~N}-\left(\mathrm{O}-\mathrm{Cl} \frac{\mathrm{K}_{2} \mathrm{CO}_{3}}{\mathrm{DMF}} \mathrm{O}_{2} \mathrm{~N}-\left(\mathrm{O}-\mathrm{O}-\left(\mathrm{O}-\mathrm{O}-\left(\mathrm{O}-\mathrm{NO}_{2}\right.\right.\right.\right.\right. \\
& \text { I } \\
& \text { I } \underset{\mathrm{Pd}-\mathrm{C}}{\stackrel{\mathrm{H}_{2} \mathrm{NNH}_{2} \cdot \mathrm{H}_{2} \mathrm{O}}{\longrightarrow}} \mathrm{H}_{2} \mathrm{~N}-\mathrm{O}-\mathrm{O}-\underset{\text { II }}{\mathrm{O}}-\mathrm{O}-\mathrm{O}-\mathrm{NH}_{2}
\end{aligned}
$$

dinitro and diamine compounds were confirmed by elemental analysis, IR, and NMR spectra. As shown in the experimental section, elemental analysis data of the dinitro and diamine compounds agreed with calculated values of their structures. In the ${ }^{1} \mathrm{H}$ NMR spectrum of BNTB (see Experimental), the absorption signals of benzene protons appear at 6.91 and $7.19 \mathrm{ppm}$. The nonfirst-order $\mathrm{AA}^{\prime} \mathrm{BB}^{\prime}$ splitting patterns of the phenylene protons are very close and appear together at 7.03 and $8.19 \mathrm{ppm}$. When the dinitro compound BNTB is converted to diamine BATB, the signal at $3.55 \mathrm{ppm}$ is peculiar to the amino group. The ${ }^{13} \mathrm{C}$ NMR spectra of BNTB and BATB both exhibit 15 peaks. However, because the spectra were very complicated, no attempts were made to assign the signal of each carbon.

\section{Preparation of Polyimides}

Polyimides were prepared by the conventional two step procedure as shown in eq 2 . In the preparation

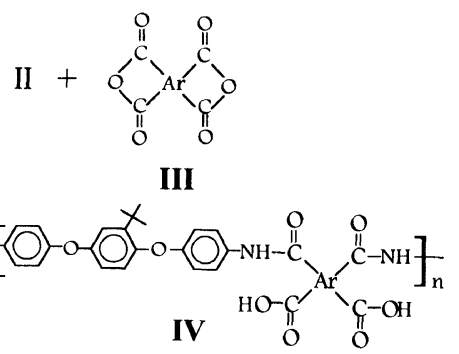



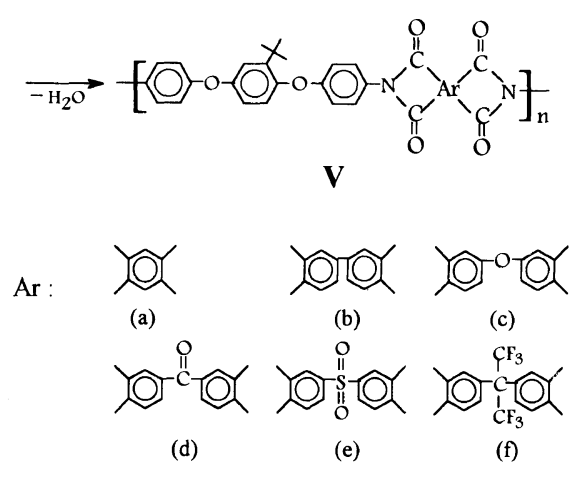

of poly(amic acid)s from aromatic diamines and dianhydrides in a polar solvent, monomer addition plays an important role for successful polymerization. As described in the study of Yang et al., ${ }^{24,25}$ the multistep addition of PMDA to the solution of a diamine yielded poly(amic acid) with higher molar mass than by reverse addition or mixing both reactants. The poly(amic acid)s $\mathrm{IV}_{\mathrm{a}-\mathrm{f}}$ were prepared by adding dianhydrides to the diamine solution as described previously. ${ }^{24,25}$ The inherent viscosities of all the poly(amic acid)s together with those of the corresponding polyimides are summarized in Table I. The inherent viscosities of the poly(amic acid)s were $0.76-1.79 \mathrm{dL} \mathrm{g}^{-1}$.

Flexible and transparent polyimide films could be obtained by thermal cyclodehydration. Alternatively, chemical conversion of poly(amic acid)s with a mixture of acetic anhydride and pyridine is also effective in obtaining polyimides. The polyimides prepared by thermal procedure had inherent viscosities of $0.52-$ $0.91 \mathrm{dL} \mathrm{g}^{-1}$ in concentrated sulfuric acid.

The elemental analysis data of these polyimides listed in Table I were generally in good agreement with the respective structures for hydrogen and nitrogen, while carbon analysis data were below their theoretical values-a phenomenon common to high-temperature polyimides.

\section{Thermal Cyclodehydration of Poly(amic acid)}

The thermal conversion of poly(amic acid) to polyimide was monitored by infrared spectroscopy. The IR films were prepared by casting $2-3$ mass $\%$ poly(amic acid) solution in DMAc onto a glass substrate and heating at $80^{\circ} \mathrm{C}$ in a hot air oven for $2 \mathrm{~h}$. The poly(amic acid) films were further dried and imidized by thermal treatment. Figure 1 shows the IR spectra of the representative poly(amic acid) $\mathrm{IV}_{\mathrm{f}}$ and corresponding polyimide $\mathrm{V}_{\mathrm{f}}$. Characteristic $\mathrm{C}=\mathrm{O}$ absorption bands appear at $c a .1777$ and $c a .1719 \mathrm{~cm}^{-1}$. The degree of poly(amic acid) to polyimide conversion was analyzed by the band ratio method. The absorbance of the asymmetric carbonyl stretch at $1777 \mathrm{~cm}^{-1}$ was compared with a reference aromatic stretch at $1500 \mathrm{~cm}^{-1}$. The percent imidization of poly(amic acid) was calculated as, ${ }^{26}$

$$
\text { percent imidization }=\frac{[A(1) / A(2)]_{t}-[A(1) / A(2)]_{t=0}}{[A(1) / A(2)]_{t=\infty}-[A(1) / A(2)]_{t=0}}
$$

where $A(1)=$ absorbance of the imide peak at $1777 \mathrm{~cm}^{-1}$, $A(2)=$ absorbance of the standard reference at 1500 $\mathrm{cm}^{-1}$, and $t=\infty$ time beyond which no further change in the imide peak at $250^{\circ} \mathrm{C}$ occurred. The percent imidizations of poly(amic acid) $\mathrm{IV}_{\mathrm{a}}$ versus curing time at various temperatures are shown in Figure 2. Almost all the amic acids were cyclized to imide rings within $20 \mathrm{~min}$ at $250^{\circ} \mathrm{C}$

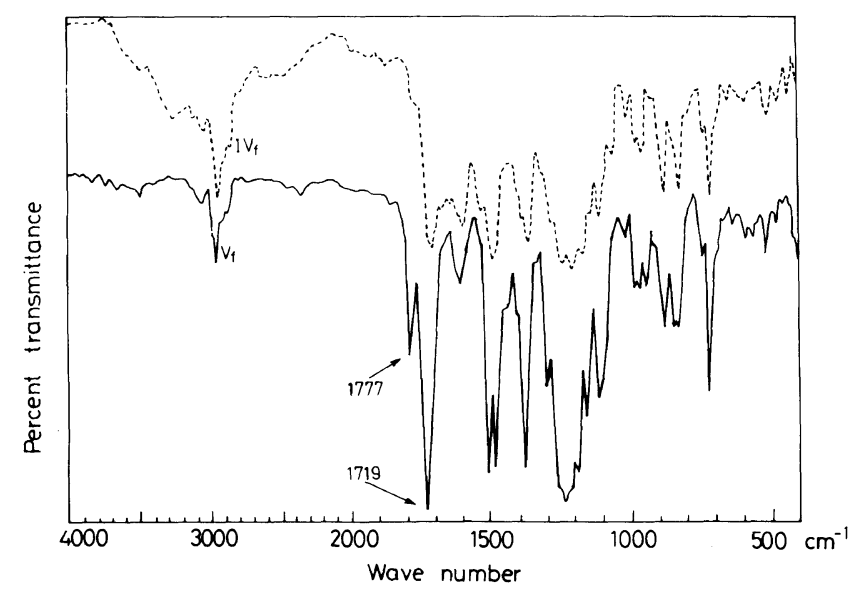

Figure 1. IR spectra of poly(amic acid) $\mathrm{IV}_{\mathrm{f}}$ and corresponding polyimide $V_{f}$.

Table I. Preparation of BATB-based polyimides

\begin{tabular}{|c|c|c|c|c|c|c|c|c|}
\hline \multirow{3}{*}{$\begin{array}{c}\text { Tetracarboxylic } \\
\text { dianhydride }\end{array}$} & \multirow{2}{*}{\multicolumn{2}{|c|}{ Poly (amic acid $)^{a}$}} & \multicolumn{6}{|c|}{ Polyimide $^{\mathrm{b}}$} \\
\hline & & & \multirow{2}{*}{ Code } & \multirow{2}{*}{$\eta_{\mathrm{inh}}{ }^{\mathrm{d}} / \mathrm{dL} \mathrm{g}^{-1}$} & \multicolumn{4}{|c|}{ Elemental analysis } \\
\hline & Code & $\eta_{\mathrm{inh}} / \mathrm{aLg}$ & & & & $\mathrm{C} \%$ & $\mathrm{H} \%$ & $\mathrm{~N} \%$ \\
\hline $\mathrm{III}_{\mathrm{a}}$ & $\mathrm{IV}_{\mathrm{a}}$ & 1.79 & $\mathrm{~V}_{\mathrm{a}}$ & 0.91 & $\begin{array}{l}\text { Found } \\
\text { Cacld }\end{array}$ & $\begin{array}{c}71.15 \\
(72.45)\end{array}$ & $\begin{array}{c}4.16 \\
(4.15)\end{array}$ & $\begin{array}{c}5.14 \\
(5.28)\end{array}$ \\
\hline $\mathrm{III}_{\mathrm{b}}$ & $\mathrm{IV}_{\mathrm{b}}$ & 1.30 & $\mathrm{~V}_{\mathrm{b}}$ & 0.74 & $\begin{array}{l}\text { Found } \\
\text { Cacld }\end{array}$ & $\begin{array}{c}74.59 \\
(75.25)\end{array}$ & $\begin{array}{c}4.31 \\
(4.29)\end{array}$ & $\begin{array}{c}4.59 \\
(4.62)\end{array}$ \\
\hline $\mathrm{III}_{\mathrm{c}}$ & $\mathrm{IV}_{\mathrm{c}}$ & 0.76 & $\mathrm{~V}_{\mathrm{c}}$ & 0.52 & $\begin{array}{l}\text { Found } \\
\text { Cacld }\end{array}$ & $\begin{array}{c}72.73 \\
(73.31)\end{array}$ & $\begin{array}{c}4.20 \\
(4.18)\end{array}$ & $\begin{array}{c}4.46 \\
(4.50)\end{array}$ \\
\hline $\mathrm{III}_{\mathrm{d}}$ & $\mathrm{IV}_{\mathrm{d}}$ & 1.40 & $\mathrm{~V}_{\mathrm{d}}$ & 0.76 & $\begin{array}{l}\text { Found } \\
\text { Cacld }\end{array}$ & $\begin{array}{c}73.22 \\
(73.82)\end{array}$ & $\begin{array}{c}4.14 \\
(4.10)\end{array}$ & $\begin{array}{c}4.38 \\
(4.42)\end{array}$ \\
\hline $\mathrm{III}_{\mathrm{e}}$ & $\mathrm{IV}_{\mathrm{e}}$ & 1.19 & $\mathrm{~V}_{\mathrm{e}}$ & 0.61 & $\begin{array}{l}\text { Found } \\
\text { Cacld }\end{array}$ & $\begin{array}{c}66.93 \\
(68.06)\end{array}$ & $\begin{array}{c}4.13 \\
(3.88)\end{array}$ & $\begin{array}{c}4.11 \\
(4.18)\end{array}$ \\
\hline $\mathrm{III}_{\mathrm{f}}$ & $\mathrm{IV}_{\mathrm{f}}$ & 1.78 & $V_{f}$ & 0.81 & $\begin{array}{l}\text { Found } \\
\text { Cacld }\end{array}$ & $\begin{array}{c}65.04 \\
(65.08)\end{array}$ & $\begin{array}{c}3.76 \\
(3.44)\end{array}$ & $\begin{array}{c}3.83 \\
(3.70)\end{array}$ \\
\hline
\end{tabular}

a Polymerization was carried out with equimolar quantities of BATB and aromatic dianhydrides to obtain 10 mass \% poly(amic acid) solutions. ${ }^{\mathrm{b}}$ Obtained by thermal cyclization from the corresponding poly(amic acid)s. ${ }^{\mathrm{c}}$ Measured in DMAc at $0.5 \mathrm{~g} \mathrm{dL}^{-1}$ at $30^{\circ} \mathrm{C}$. ${ }^{\mathrm{d}}$ Measured in concentrated sulfuric acid at $0.5 \mathrm{~g} \mathrm{dL}^{-1}$ at $30^{\circ} \mathrm{C}$. 
and $230^{\circ} \mathrm{C}$. When a sample was heated at $180^{\circ} \mathrm{C}$ for $100 \mathrm{~min}$, the imide peak grew to approximately $71 \%$ of its final size. The sample was then cured at $210^{\circ} \mathrm{C}$ for up to $100 \mathrm{~min}$. The degree of imidization increased, indicating that the imidization reaction was not completed at $180^{\circ} \mathrm{C}$.

\section{Properties of Polyimides}

The solubility of these polyimides was studied qualitatively. The results are shown in Table II. Polyimides prepared by the chemical conversion method had better solubility compared with those by the thermal procedure. Polyimides $\mathrm{V}_{\mathrm{a}-\mathrm{d}}$ were almost insoluble in organic solvents but dissolved in concentrated sulfuric acid. Polyimides $\mathrm{V}_{\mathrm{e}}$ and $\mathrm{V}_{\mathrm{f}}$ containing sulfone and hexafluoroisopropylidene linkage exhibit excellent solubility toward test solvents. For comparison, polyimide $\mathrm{VI}_{\mathrm{e}}$ was prepared by the condensation of 1,4-bis(4-aminophenoxy)benzene with SDPA through chemical cyclodehydration.

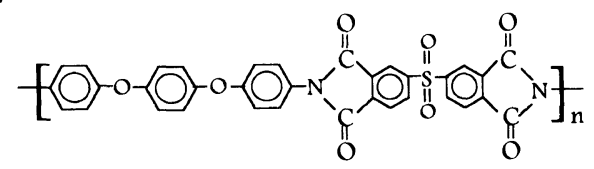

$\mathrm{VI}_{\mathrm{e}}$

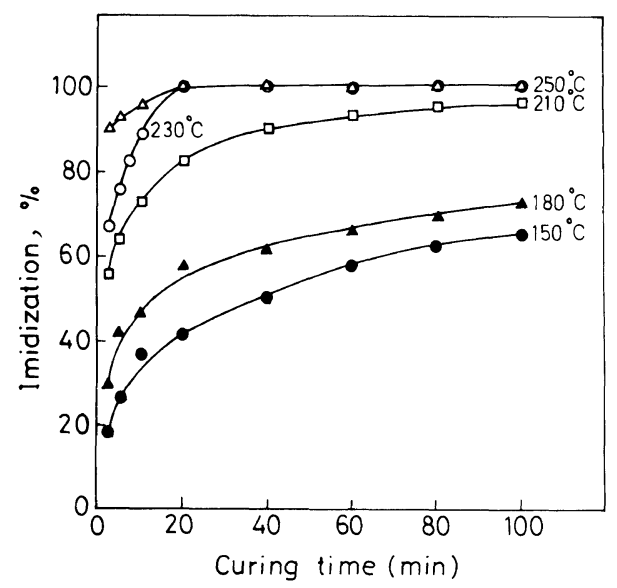

Figure 2. Variation in $\%$ imidization of poly (amic acid) $I_{\mathrm{a}}$ heated at various time intervals and various temperatures.
The results of the solubility test on different solvents are also listed in Table II. Comparing the results from tert-butyl substituted polyimide $\mathrm{V}_{\mathrm{e}}$ and analogous polyimide $\mathrm{VI}_{\mathrm{e}}$ shows that tert-butyl substituent incorporated into the polyimide indeed increased its solubility.

Crystallinity of the polymers was examined by wideangle X-ray diffraction diagrams. The polyimide films obtained by thermal imidization were used as the samples. All polyimide films were amorphous. These results could be explained by the fact that the randomly distributed direction of the substituents reduces the symmetry within the polymer chain and leads to lower stereoregularity. ${ }^{16-21,27}$ For comparison, the analogous polyimide $\mathrm{VI}_{\mathrm{a}}$ having a phenylene ring without substituent and polyimide $\mathrm{VII}_{\mathrm{a}}$ having symmetric di-tertbutyl substituents on phenylene ring were prepared by the polycondensation of 1,4-bis(4-aminophenoxy)benzene or 1,4-bis(4-aminophenoxy)-2,5-di-tert-butylbenzene with PMDA. ${ }^{31}$

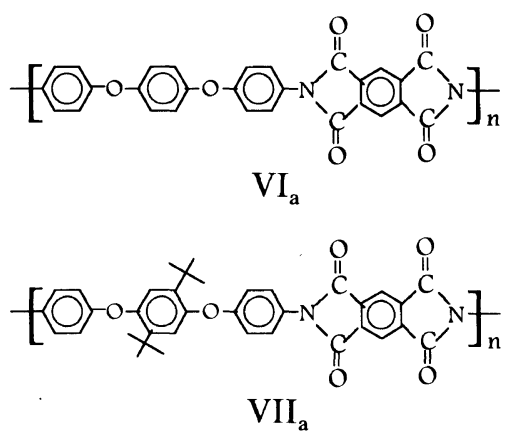

The X-ray diffraction diagrams of polyimides $V_{a}, V I_{a}$, and VII $_{a}$ were shown in Figure 3 . It could be seen that the crystallinity of $\mathrm{VI}_{\mathrm{a}}$ is slightly greater than $\mathrm{V}_{\mathrm{a}}$. This may be due to the absence of a bulky substituent that hinders packing of the polymer chain, therefore leading to greater stereoregularity and crystallinity. It was also observed that polyimide $\mathrm{VII}_{\mathrm{a}}$ has the highest degree of crystallinity among the other polyimides $\mathrm{V}_{\mathrm{a}}$ and $\mathrm{VI}_{\mathrm{a}}$ due to its symmetric substituents. ${ }^{31}$

The tensile properties of the polyimide films prepared by the thermal treatment are summarized in Table III. The polyimides $\mathrm{V}_{\mathrm{a}}-\mathrm{V}_{\mathrm{f}}$ films had tensile strength of

Table II. Solubility of polyimides ${ }^{a}$

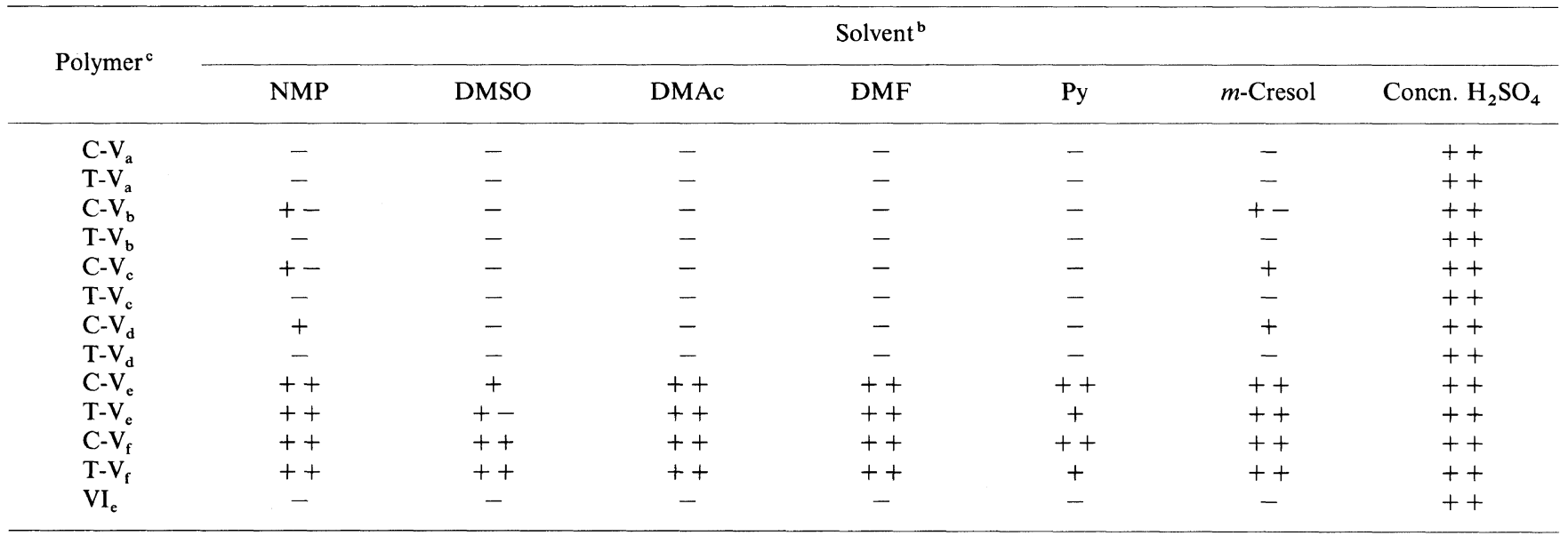

a Solubility: ++ , soluble at room temperature; + , soluble on heating; +- , partial soluble on heating; - , insoluble. ${ }^{\mathrm{b}}$ Abbreviations: NMP, $N$-methyl-2-pyrrolidinone; DMSO, dimethyl sulfoxide; DMF, $N, N$-dimethylformamide; Py, pyridine. ${ }^{\mathrm{c}}$ Polyimides obtained by the chemical cyclodehydration method are designated by $\mathrm{C}$ while those obtained by the thermal means, by $\mathrm{T}$. 


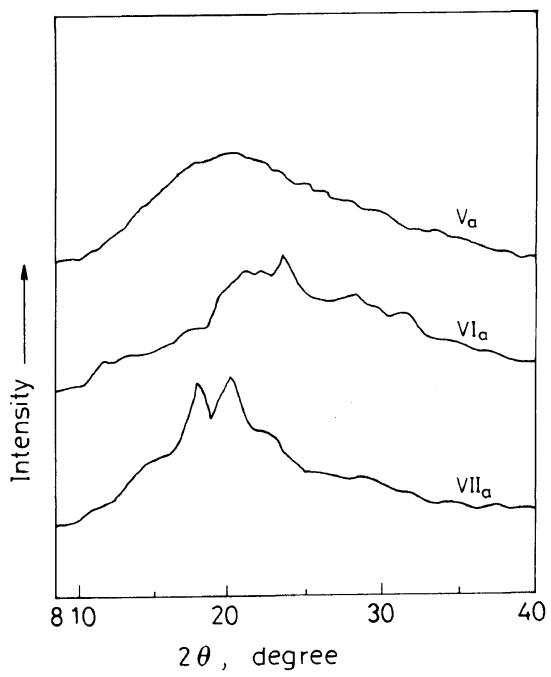

Figure 3. Wide-angle X-ray diffractograms of polyimides.

Table III. Mechanical properties of polyimides

\begin{tabular}{|c|c|c|c|}
\hline \multirow{2}{*}{ Polymer } & $\begin{array}{l}\text { Tensile } \\
\text { strength }\end{array}$ & $\begin{array}{l}\text { Elongation } \\
\text { at break }\end{array}$ & $\begin{array}{c}\text { Initial } \\
\text { modulus }\end{array}$ \\
\hline & $\mathrm{MPa}$ & $\%$ & $\mathrm{GPa}$ \\
\hline$V_{a}$ & 168 & 6 & 2.18 \\
\hline$V_{b}$ & 208 & 7 & 1.92 \\
\hline$V_{c}$ & 122 & 5 & 1.93 \\
\hline$V_{d}$ & 169 & 9 & 1.97 \\
\hline$V_{e}$ & 196 & 6 & 2.35 \\
\hline$V_{f}$ & 150 & 3 & 2.68 \\
\hline $\mathrm{VI}_{\mathrm{a}}$ & 160 & 6 & 2.07 \\
\hline $\mathrm{VII}_{\mathrm{a}}$ & $-^{a}$ & - & - \\
\hline
\end{tabular}

${ }^{a}$ Could not be determined due to brittleness of casting film.

$122-208 \mathrm{MPa}$, elongation at break of $3-9 \%$, and initial modulus of $1.92-2.68 \mathrm{GPa}$. Most polymer films exhibited high tensile strength, high modulus and low elongation; thus they could be considered as hard and strong materials. The tensile properties of analogous polyimides $\mathrm{VI}_{\mathrm{a}}$ and $\mathrm{VII}_{\mathrm{a}}$ are also included in Table III. The mechanical properties of polyimide $V_{a}$ are similar to polyimide $\mathrm{VI}_{\mathrm{a}}$ and superior than brittle polyimide VII $_{\mathrm{a}}$.

The thermal behavior of the polyimides prepared by thermal cyclodehydration was evaluated by differential scanning calorimetry (DSC) and thermogravimetric (TG) analysis. Table IV summarizes the thermal transition data of all the polyimides. All the polyimides showed similar patterns of decomposition with no mass loss below $450^{\circ} \mathrm{C}$ in an air or nitrogen atmosphere. The decomposition temperatures of $10 \%$ mass loss were in the range of $479-522^{\circ} \mathrm{C}$ in nitrogen and $480-528^{\circ} \mathrm{C}$ in air. The $10 \%$ mass loss temperature in air is similar to that in nitrogen, indicating that polyimides based on BATB showed thermooxidative stability in air. It was observed that polyimide $\mathrm{V}_{\mathrm{e}}$ containing a sulfone connecting groups, had the lowest decomposition temperature and aerobic char yield. The SDPA-based polyimide $\mathrm{V}_{\mathrm{e}}$ seemed to show lower thermal stability as reported in the literature. ${ }^{5,11,12,25}$ The comparative TGA curves of polyimides $\mathrm{V}_{\mathrm{a}}$ and $\mathrm{VI}_{\mathrm{a}}$ are indicated in Figure 4. They showed similar behavior below $460^{\circ} \mathrm{C}$. As expected, the
Table IV. Thermal properties of BATB-based polyimides

\begin{tabular}{|c|c|c|c|c|}
\hline \multirow{2}{*}{ Polyimide } & \multirow{2}{*}{$\begin{array}{r}T_{\mathrm{g}}^{\mathrm{a}} \\
{ }^{\circ} \mathrm{C}\end{array}$} & \multicolumn{2}{|c|}{$\frac{\text { Decomposition temp }^{\mathrm{b}}}{{ }^{\circ} \mathrm{C}}$} & \multirow{2}{*}{$\frac{R_{800} \mathrm{c}}{\%}$} \\
\hline & & In $\mathrm{N}_{2}$ & In air & \\
\hline $\mathrm{V}_{\mathrm{a}}$ & 268 & 512 & 515 & 48 \\
\hline $\mathrm{V}_{\mathrm{b}}$ & 261 & 522 & 522 & 52 \\
\hline $\mathrm{V}_{\mathrm{c}}$ & 240 & 521 & 517 & 46 \\
\hline$V_{d}$ & 247 & 518 & 517 & 61 \\
\hline $\mathrm{V}_{\mathrm{e}}^{\mathrm{a}}$ & 246 & 479 & 480 & 43 \\
\hline$V_{f}$ & 248 & 522 & 528 & 53 \\
\hline
\end{tabular}

${ }^{a}$ Glass transition temperature $\left(T_{\mathrm{g}}\right)$ measured on DSC at a heating rate of $20^{\circ} \mathrm{C} \mathrm{min}^{-1}$. ${ }^{\mathrm{b}}$ Temperature at which $10 \%$ mass loss was recorded on TG at a heating rate of $20^{\circ} \mathrm{C} \mathrm{min}^{-1}$. ${ }^{\mathrm{c}}$ Residual mass $\%$ at $800^{\circ} \mathrm{C}$ in nitrogen.

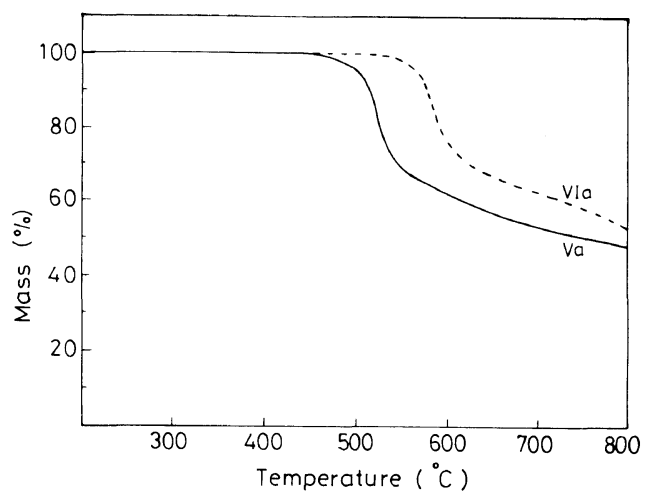

Figure 4. TGA curves of polyimides $\mathrm{V}_{\mathrm{a}}$ and $\mathrm{VI}_{\mathrm{a}}$ with heating rate of $20^{\circ} \mathrm{C} \mathrm{min}^{-1}$ in nitrogen.

tert-butyl substituted polyimide $\left(\mathrm{V}_{\mathrm{a}}\right)$ began to decompose at lower temperatures than unsubstituted polyimide $\left(\mathrm{VI}_{\mathrm{a}}\right)$ but it is worth noting that the polyimides $\mathrm{V}_{\mathrm{a}}$ left a similar char residue compared with polyimide $\mathrm{VI}_{\mathrm{a}}$. This implies that there is possibility of crosslinking between the polymer chains during the degradation process. ${ }^{28,29} \mathrm{TG}$ analysis also shows that $\mathrm{VII}_{\mathrm{a}}$ has greater mass loss and less char yield than $\mathrm{V}_{\mathrm{a}}$ and $\mathrm{VI}_{\mathrm{a}} \cdot{ }^{31}$ The polyimides had $T_{\mathrm{g}} \mathrm{s}$ in the $240-268^{\circ} \mathrm{C}$ range. This order was comparable to the decreasing order of stiffness and polarity of the polymer backbones. Polyimides $\mathrm{V}_{\mathrm{e}}$ and $\mathrm{V}_{\mathrm{f}}$ had higher $T_{\mathrm{g}} \mathrm{s}$ than oxy-bridge containning polyimide $\mathrm{V}_{\mathrm{c}}$. This may be attributed to the intermolecular force of sulfonyl groups and the steric hindrance of hexafluoroispropylidene bridging moieties. ${ }^{30}$ Glass transition temperatures of $\mathrm{VI}_{\mathrm{a}}$ and $\mathrm{VI}_{\mathrm{b}}$ were measured to be 286 and $298^{\circ} \mathrm{C}$, respectively. The order of $T_{\mathrm{g}} \mathrm{s}$ among $\mathrm{V}_{\mathrm{a}}, \mathrm{VI}_{\mathrm{a}}$, and $\mathrm{VI}_{\mathrm{b}}$ is $\mathrm{VI}_{\mathrm{b}}>\mathrm{VI}_{\mathrm{a}}>\mathrm{V}_{\mathrm{a}}$, corresponding to the order of crystallinity $\mathrm{VI}_{\mathrm{b}}>\mathrm{VI}_{\mathrm{a}}>\mathrm{V}_{\mathrm{a}}$. In general, the $T_{\mathrm{g}}$ increased with crystallinity.

\section{CONCLUSIONS}

A novel diamine, 1,4-bis(4-aminophenoxy)-2-tertbutylbenzene, containing bulky tert-butyl substituent was successfully prepared in high purity and high yield in this study. Poly(amic acid)s were obtained in moderate to high molar mass. All poly(amic acid)s could be thermally converted to transparent, tough, and flexible polyimide films with excellent tensile properties. Polyimides derived from SDPA and 6FDA had good solu- 
bility in a few polar organic solvents. The use of bulky monosubstituted diamine into the polymer chain results in decrease in crystallinity and the glass transition temperature.

Acknowledgment. The authors thank the National Science Council of the Republic of China for supporting this work.

\section{REFERENCES}

1. P. E. Cassidy, "Thermally Stable Polymers," Dekker, New York., N.Y., 1980.

2. M. I. Bessonov, M. M. Koton, V. V. Kudryavtsev, and L. A Laius, Ed., "Polyimides," Consultants Bureau, New York, N.Y., 1987.

3. C. E. Sroog, J. Polym. Sci., Macromol. Rev., 11, 161 (1976).

4. W. A. Feld, B. Ramalingam, and F. W. Harris, J. Polym. Sci., Polym. Chem. Ed., 21, 319 (1983).

5. Y. Imai, N. N. Maldar, and M. Kakimoto, J. Polym. Sci., Part A, Polym. Chem., 22, 2189 (1989).

6. N. D. Ghatge, B. M. Shinde, and U. P. Mulik, J. Polym. Sci., Polym. Chem. Ed., 22, 3359 (1984).

7. T. Takekoshi, J. G. Wirth, D. R. Heath, J. E. Kochanowski, J. S. Manello, and M. J. Webber, J. Polym. Sci., Polym. Chem. Ed., 18, 3069 (1980).

8. J. P. Critchley and M. A. White, J. Polym. Sci., Polym. Chem. Ed., 10, 1809 (1972).

9. T. L. St. Clair, A. K. St. Clair, and E. N. Smith, Polym. Prepr., Am. Chem. Soc., Div. Polym. Chem., 17, 359 (1976).

10. V. L. Bell, B. L. Stump, and H. Gager, J. Polym. Sci., Polym. Chem. Ed., 14, 2275 (1976)
11. H. J. Jeong, Y. Oishi, M. Kakimoto, and Y. Imai, J. Polym. Sci, Part A, Polym. Chem., 29, 39 (1991).

12. H. J. Jeong, M. Kakimoto, and Y. Imai, J. Polym. Sci., Part A, Polym. Chem., 29, 1691 (1991).

13. Y. Oishi, M. Ishida, M. Kakimoto, and Y. Imai, and T. Kurosaki, J. Polym. Sci., Part A, Polym. Chem., 30, 1027 (1992).

14. Y. Imai and M. Kakimoto, Polym. Plast. Technol. Eng., 28, 371 (1989).

15. M. Sato and M. Yokoyama, Eur. Polym. J., 15, 733 (1979).

16. P. K. Bhowmik, E. D. T. Atkins and H. Han, Polym. Prepr, Am. Chem. Soc., Div. Polym. Chem., 36(2), 326 (1995).

17. Z. G. Li, J. E. Mclntyre, and J. G. Tomka, Polymer, 34, 551 (1993).

18. T. Heitz, P. Rohrbach, and H. Hoecker, Makromol. Chem., 190, 3295 (1989).

19. W. Heitz and N. Niessner, Makromol. Chem., 191, 225 (1990).

20. H. W. Schmidt and D. Guo, Makromol. Chem., 189, 2029 (1988).

21. W. Risse and D. T. Sogah, Macromolecules, 23, 4029 (1990).

22. D. J. Liaw, J. Polym. Sci., Part A, Polym. Chem., 33, 605, (1995).

23. K. H. Becker and H. W. Schmidt, Polym. Mater. Sci. Eng., 66 , 303 (1992).

24. C. P. Yang and S. H. Hsiao, J. Appl. Polym. Sci., 30, 2883 (1985).

25. C. P. Yang and W. T. Chen, Macromolecules, 26, 4865 (1993).

26. S. E. Delos, R. K. Schellenberg, J. E. Smedley, and D. E. Kranbuehl, J. Appl. Polym. Sci., 27, 4295 (1982).

27. D. J. Liaw and W. C. Shen, Angew. Makromol. Chem., 199, 171 (1992).

28. F. Keitoku, M. Kakimoto, Y. Imai, J. Polym. Sci., Part A, Polym. Chem., 32, 317 (1994).

29. S. H. Hsiao, C. P. Yang, and C. K. Lin, J. Polym. Res., 2(1), 1 (1995).

30. C. P. Yang and J. H. Lin, J. Polym. Sci., Part A, Polym. Chem., 30, 1027 (1992).

31. D. J. Liaw and B. Y. Liaw, J. Polym. Sci., Part A, Polym. Chem., submitted. 